\title{
A Guerra e sua LegITIMIDAdE: CONSIDERAÇÕES SOBRE O Conselho de Segurança da ONU e a Guerra Legal ${ }^{1}$
}

\section{Heloisa Helena de Almeida Portugal ${ }^{2}$}

\section{SUMÁRIO:}

Apresentação Temática; 1.1 A Sociedade Internacional e sua Institucionalização origens sociológicas da ONU; 1.2 A Tutela da Guerra pelo Direito Internacional - do direito de Guerra ao Conselho de Segurança da ONU; 1.3 A licitude nas intervenções Unilaterais dos Estados para a Defesa de um Direito. Referências Bibliográficas.

\section{RESUMO:}

Analisa-se no presente trabalho a dimensão legal do conflito bélico entre os Estados Unidos da América e o Iraque, ocorrido em 2003, como instrumento de analise da tutela jurídica da Guerra no Direito Internacional do século XXI. Para tanto, contextualizam-se os fatos recentes da histórica no final do século XX e decorrentes transformações na sociedade internacional, analisando a formação da ONU como necessidade social de institucionalização. Por fim, verifica-se os parâmetros legais da Guerra, os princípios basilares na solução de conflitos para se chegar ao questionamento da legalidade da II guerra do golfo.

Trabalho especialmente apresentado para o $2^{\circ}$ Congresso Brasileito de Direito Internacional, realizado em Curitiba-Pr, se 25 a 28 de agosto de 2004, organizado pela Academia Brasileira de Estudos em Direto Internacional -... ABEDI.

2 Mestre em Direito Negocial pela Universidade Estadual de Londrina e professora de Direito Internacional na Faculdade Paranaense - FACCAR, email: apportugal@ldapaln.com.br. 


\section{Apresentação Temática}

O paradigma da globalização traz em si uma pretensão universalista constatada não apenas nos discursos liberais dos dirigentes estatais, mas também em seus efeitos. Desde o final da segunda grande guerra, a sociedade internacional vem se complexizando e trazendo como fundamentos a autodeterminação dos povos e a cooperação estatal.

Os Estados, principalmente os novos criados a partir do término da segunda guerra, passam a ter como necessidade a interdependência criando-se um ambiente propicio para se consubstanciar o paradigma da globalização, ou seja, liberalização comercial, relativização da soberania (em tese), desenvolvimento comunicativo e tecnológico. As ações passam a ser em larga escala e, via de conseqüência seus efeitos.

A sociedade internacional, caracterizada por sua horizontalidade, e abertura, passa a se institucionaljzar e agtupar-se em uniōes econômicas-comerciais com vistas ao alcance das vantagens comparativas e competitivas, ou seja, o desenvolvimento econômico e comercio internacional.

Quanto mais complexa se torna a sociedade mais se revela a necessidade de regulamentaçẫo e, ainda, a dimensão de justiça e legitimidade do Direito toma-se mais evidente e necessária.

A institucionalização social requer a construção de um sistema normativo e, neste ponto, florescem os questionamentos sobre a existencia e natureza do Diteito Internacional, pois além da determinação do conteúdo essencial da notma, em qualquer sistema jurídico deve-se verificar sua efetividade.

Faz-se mister a dimensão sociológica do Direito, haja vista que o questionamento provém essencialmente do fato de que tanto os valores que incorporam e revelam do que é "justo", quanto a avaliação dos resultados da regulação jurídicas são relativos.

A adequação do sistema jurídico e, via de conseqüência sua eficácia e efetividade, estão diretamente vinculadas à condição de atender e preservar os valores vigentes em uma dada sociedade, bem como suas necessidades.

Neste sentido, analisar a sociedade internacional como se apresenta neste inicio de século XXI e considerar as transformações e mudanças paradigmáticas que vêm ocorrendo desde a década de 50 do século XX, torna-se essencial para se verificar a legitimidade da guerra e a efetividade do Conselho de Segurança da ONU.

O foco de análise passa a ser então, o conflito bélico entre EUA e Iraque, desde a intervenção da ONU na denominada guerra do Golfo culminando com a invasão norteamericana ao Itaque em 20 de março de 2003 e decorrente ocupação. Mais especificamente, a analise da atuação do Conselho de Segurança da ONU diante dos fatos em face do sistema jurídico internacional e, sua instrumentalidade adequada e efetiva no alcance da paz mundial. 


\subsection{A Sociedade Internacional e sua institucionalização - origens sociológicas da $\mathrm{ONU}$}

A segunda década do século XX foi marcada por transformações fundamentais na sociedade internacional e, se o direito é manifestação da vida social, deve-se antes de se analisar qualquer instituto ou fato jurídico, conhecer o ambiente em estudo.

Através de uma visão histótica da formação das sociedades contemporâneas e suas relações, pode-se observar o processo de construção do espaço geopolítico, onde são fatores relevantes o meio de trabalho, o espaço, o planejamento do espaço e os vestígios deixados pelas relações sociais passadas. Nesta configuração pode-se vislumbrar a relação entre o espaço e o poder, onde o primeiro é a base material do poder exercido por grupos hegemônicos da sociedade.

O poder implica no domínio de um espaço territorial (no passado) ou de valores técnicos, financeiros e ideológicos (Séc. XX e XXI). De forma que, as relações humanas constroem-se sob e sobre, a luta pelo poder, onde as sociedades criam estruturas mais ou menos complexas para justificar e fundamentar a dominação.

Para RENÉ ARMAND DREIFUSS ${ }^{3}$ a reestruturaçêes econômicas, reformulações políticas e reconfiguraçôes societárias, decorrentes de mundialização (sociocultural existencial) ede globalização (tecnoprodutizue econômica) requerem estabilidadee previsibilidade institucional, econômicae societária.

Diante disso, verifica-se que a sociedade internacional formada basicamente por Estados soberanos caracteriza-se hoje pelo associativismo entre estes enres e, entram em pauta temas transnacionais, como o aproveitamento de recursos bioenergéticos, comunicações, terrorismo, tecnologia e a reemergencia de identidades nacionais, étnicas e religiosas.

A transnacionalidade e o idealismo da complementariedade entre os Estados, principalmente a idéia de associação para se alcançar a competitividade internacional faz com que a sociedade internacional se ins titucionalize e crie organismos internacionais, dotados de personalidade jurídica e abrangência planetária, como a ONU, OEA e SdN.

Analisando o processo de institucionalização da sociedade internacional, PATRICK DAILLER ${ }^{4}$ afirma que sua organização política resultou da reação à anarquia emergida dos conflitos internacionais aliada á insuficiência da doutrina do equilibrio. De forma que o fim último do direito e de toda sociedade consiste na solução de conflitos e a convergência para a pacificação, trouxeram a tona a ambição de integrar Estados soberanos em um sistema juridico unitário.

3 DREIFUSS, RENÉ ARMAND A época das perplexidades: mundialização, globalização e planetarização - novos desafios. Petrópolis, RJ : Vozes, 1996, p 244.

4 DINH, Nguyen Quoc; DAILLER, Patrick Et PELLET, Alain. Direito Internacional Publico, tradução do original Droit Internacional Public por Vitor Marques Coelho, Lisboa : Fundação Calouste Gulbemkain, 1999, p.61. 
Ao se idiealizar a Organização das Nações Unidas, os Estados vencedores da segunda grande guerra estavam imbuídos de tal idealismo e já, de certa forma experientes, buscando, à imagem das estruturas da sociedade estatal, criar um sistema jurídico capaz de prevenir $\mathrm{e}$ resolver conflitos de interesses de seus membros.

Destarte, faz-se necessário superar o interestatalismo e ainda, a formação de uma organização política centralizada que disponha de meios de coação e de persuasão sobre os Estados, bem como um poder de coordenação das instituições técnicas e regionais.

Neste ponto encontra-se a celeuma e a dicotomia. De um lado tem-se a vontade e o interesse dos Estados em se institucionalizar, de outro estes mesmos Estados convivem e co-habitam e têm como fundamento próprio a soberania. Cabe então, ao direito internacional buscar equilibrar tais forças através de um sistema jurídico singular, mas não inexistente.

Singular, primeiro por ter o poder legiferandi descentralizado e, como em qualquer norma jurídica, as normas internacionais são objeto de um processo formal de elabotação no qual intervêm por primeiro os Estados, simultaneamente autores e destinatários dessas regras ${ }^{3}$. E ainda, singular por seu sistema de sanção que no presente traballo será analisado en capitulo próprio.

Com a presente preocupação de conferir poderes decisionais e de ação às organizações estatais cria-se a Organização das Nações Unidas em 24 de outubro de 1945, composta por 51 Estados soberanos e com pretensões universalistas.

Após 58 anos de existência, na proximidade de seu aniversário de quase sexagenária, e quase a totalidade dos Estados entes da sociedade internacional (são 191) é assaz importante uma reflexão sobre sua atuação e efetividade na solução de conflitos.

\subsection{A Tutela da Guerra pelo Direito Internacional - do Direito de Guerra ao Conselho de Segurança da ONU.}

$O$ antagonismo de interesses entre homens ou sociedades gera um conflito, este objeto do Direito. Uma vez que, para se estabelecer a paz, há que se estabelecer o equilíbrio, há que se ter em cada parte a satisfação de seus interesses. Ao se criarem as instituições jurídicas objetiva-se instrumentalizar e balizat a práxis de solução de litígios.

Todavia, o ser humano é naturalmente conflitivo haja vista ser insatisfeito e anseia galgar níveis, em sua própria escala de valores, mais elevados do que se encontra. De forma que, no ambiente internacional tal assertiva torna-se mais evidenciada em se tratando de

5 DINF, Nguyen Quoc; DAllleR, Patrick Et PELlet, Alain. Op. Loc. Cit. p.82.

"Dacios pesquisados e disponiveis no site da Organizaçẫo das Nações Unidas in: http://wwwiunorg/ spanish/aboutun/growth.htm, acessado em 01 de juho de 04 . 
coexistência de entidades soberanas, organizações criadas por estas entidades e os homens individualmente considerados.

Conjugar estes interesses traz a idéia de um estado de paz tênue ou ainda, um latente estado de conflito. Quando as formas pacificas de solução de conflitos são insuficientes para alcançar o equilubrio, o homem busca a utilização do uso da força para atingir seu objetivo.

Assim, de maneira sintética, busca conceituar a guerra no âmbito do direito internacional. Em uma análise preliminar, consiste na luta armada entre naçôes, ou entre partidos de uma mesmanacionalidade ou de etnias diferentes, com ofim de imporsupremacia ou salvaguardar interesses materiais ou ideológicos.

Ensina CELSO D. ALBUQUERQUE DE MELLO que a guerra contem duas concepçôes: a) a subjetivista (Strupp) afirma que a guerra só existe quando báo "anumus belligerandi", que sozinho cria a guerra; b) a objetivista (Despagnet) considera que a prática de atos de guerra cria o estado deguerra, independente da intenção.

Verifica-se attavés dos fatos históricos que a existência da guerra está condicionada aos dois elementos, o subjetivo e objetivo, vez que o uso da força armada sem a formação do estado de guerra, não a caracteriza. Acrescentando-se ainda que o conflito inicia-se pela vontade do Estado.

A realidade vivenciada no final do século XX e neste início de século XXI é caracterizada por uma revisão nas matrizes de rivalidades, vez que a dualidade norte-americano-suviético perdeu seu fundamento com a intensificação das relações de cooperação. Verifica-se a reformulação estratégica através de fundamentos étnicos, religiosos ou nacionais e ainda, a luta pelo domínio do poder nos temas transnacionais retro mencionados, como os biocombustiveis e matrizes energéticas".

No estado de paz tênue ou de guerra latente em que se encontra a sociedade internacional neste século XXI, explica-se pelo fato de que, devido a reformulação do fundamento de disputa acima descrito, os conflitos passam a ser locais. E, devido ao paradigma da globalização, seus efeitos passam a ser mundiais.

Insere-se neste contexto a pretensão da sociedade internacional, por intermédio da ONU e de seu Conselho de Segurança, de se chegar a prevenção de conflitos e ao que se denomina de guerra legal ou legitima.

No âmbito do sistema jurídico internacional existem hoje princípios fundamentais que buscam preservar o estado de paz, dentre eles a solução pacífica de conflitos como

7 HOUASS, Antonio e VILLAR, Mauto de Salles. Dicionário Houaiss da Língua Portuguesa, elaborado pelo instituto Antonio Houaiss de Lexicografia. Rio de Janeiro : Objetiva, 2001, p.1495.

* DRETFUSS, RENÉ ARMAND Op. Loc. Cit, p 249. 
corolário das relações internacionais, utilizando-se de mecanismos diplomáticos e jurisdicionais internacionais e, somente como via de exceção o uso da coação?.

A interdição do uso da força nas relações internacionais foi elevada ao nível de norma imperativa e, a forma de solução pacífica de litígios adquiriu o mesmo caráter. Já na Convenção para Resolução de Conflitos Internacionais, assinada em Haia em 1907, pode se verificar tal princípio:

Art. $1^{\circ}$ - tendo em vista prevenir tanto quanto possível o recurso à força nas relaçōes entre os Estados, as potências contratantes concordam em envidar todos os seus esforços para assegurar a resolução pacífica dos confliros internacionais.

Tal fundamento encontra-se reafirmado na Carta das Nações Unidas em seus Arts. $2^{\circ}, \$ 3^{\circ}$ e 33 e ainda, votado em Assembléia Geral na Declaração relativa aos princípios de direito internacional no que respeita ás relações amigáveis e à cooperação entre Estados ${ }^{10}$, firmada em 24 de outubro de 1970:

Todos os Estados devem solucionar os seus conflitos internacionais com os outros Estados por meios pacíficos de tal modo que a paz e a segurança intemacionais, assim como a justiça, não sejam postas em perigo.

Neste sentido o artigo 33 da Carta das Nações Unidas ${ }^{11}$ traça uma lista não restritiva das formas de solução pacífica sem impor qualquer uma. De forma que, os Estados utilizam da melhor vontade os processos politicos do que os processos jurídicos, compreendendo resoluções jurisdicionais através de tribunais de exceção e da Corte de Haia.

O efeito reflexo da utilização dos princípios acima elencadas consiste no questionamento se o uso da força tornou-se um ilícito para o direito internacional. Decisão antes, na esfera da soberania dos Estados, passa a depender de legitimidade frente ao sistema jurídico da Carta das Nações Unidas.

Se a guerra era conceituada como um ato de vontade dos Estados, no âmbito da Carta deve ser considerada como um ato de vontade condicionada a aprovação (ou legitimação) pelo Conselho de Segurança.

Sob a récnica jurídica, o tecurso à coação nas relações internacionais, com ou semo emprego da força material, revela o problema da sanção do Direito Internacional, ou seja, se não há a ameaça do conflito bélico, como dantes, os meios destinados a assegurar a eficácia do sistema jurídico tornam-se debeleis.

9 DINH, Ngryen Quoc; DAILLER, patrick Et PELLET, Alain. Op. Loc. Cit. p.655.

10 DINH, Nguyen Quoc; DAILLER, Patrick Et PELlET, Alain. Op. Loc. Cit. p.722.

11 Texto integral da Carta das Nações Unidas disponivel no site oficial da ONU in: http://urww.un.org/ spanish/aboutun/charter/index.htm 
No direito internacional clássico existia como princípio e decorrência da soberania estatal a liberdade de fazer guerra. $O$ abuso das represálias e os efeitos danosos principalmente da segunda grande guerra fez con que os Estados se auto-limitassem através do Conselho de Segurança da ONU. Transferindo a esta entidade o poder de declarar possível o uso da força. A auto comando de guerra passa a ser do Consello de Segurança da ONU.

No plano normativo, tal proibição consta do Art. $2^{\circ}, \$ 4^{\circ}{ }^{12}$ : Os membros da Organização abstêm-se, nas suas relaçóes internacionais, de recorrer à a meaça ou ao emprego da força, seja contra a integridadeternitonial ou a independência politicade um. Estado,sejade qual lquer outraforma incompatínel com os objetivos das Nações Unidas.

Porém, há três exceções à proibição do uso da força, duas estabelecidas na própria Carta e outra decorrente do desenvolvimento do direito internacional.

A primeira exceção está no artigo 51 da Carta, que estabelece que nada afasta de um Estado seu direito inerente de autodefesa individual ou coletivo contra um ataque armado ocorrido contra sua integridade territorial ou independência política, denominada de legítima defesa segundo a carta $^{13}$.

A segunda exceção decorre do Capítulo VII da Carta, segundo o qual o Conselho de Segurança (que tem a responsabilidade primária de manter a paz mundial) pode considerar determinada situação um ato de agressão, uma ameaça à paz ou quebra da paz. Nessas situações o Conselho de Segurança pode determinat sanções contra o Estado que infringiu a lei intetnacional contra a paz e seguridade internacional, estabelecendo sanções que podem chegar até ao uso da força (ação militar), por tropas das Nações Unidas (como no caso da Guerra da Coréia) ou autorizando Estados ou Organizações Internacionais a executá-las, como tem sido a prática recente do Conselho de Segurança. Sendo este o ponto mais preciso da presente análise.

A terceira exceção decorre do desenvolvimento do direito internacional quando da possibilidade do uso da força contra um Estado, quando há um enorme desastre humanitário com a perda em larga escala de vidas humanas, estando o Conselho de Segurança inerte ou inapto a tomar as providências necessárias (como no caso ultrajante de Ruanda) e nada, a não ser uma força militar, pode impedir tal catástrofe, como nos casos de Kosovo, Norte do Iraque na região dos Curdos (1991) e L.jbéria ${ }^{14}$.

12 Texto integral da Caxta das Naçöes Unidas disponivel no site oficial da ONU in: http://www.un.org/ spanish/aboutun/charter/index.htm.

13 MELLO, Celso D de Albuquerque.Curso de Direito Internacional Público, $2^{\circ}$ vol., $13^{\circ}$ edição revista e aumentada, Rio de Janeiro: Renovar, 2001, p.1434.

14 SWINARSKI, Christophe. A Norma ea Guerra : palestras sobre direito internacional humanitário. Porto Alegre: Sergio Antonio Fabris Editor, 1991, p. 12 
Para o sistema jurídico internacional contemporâneo, são compativeís com a Carta os empregos da força decididos pelos órgãos competentes da ONU, nos limites das funções e dos poderes que thes são atribuídos tendo em vista a manutenção da paz.

\subsection{A Licitude nas Intervenções Unilaterais dos Estados para a Defesa de um Direito}

No âmbito do artigo 51 da Carta das Nações Unidades, a primeira hipótese acima descrita, bem como na autorização pelo Conselho de Segurança da ONU a licitude da intervenção armada passa a ser questionada, vez que incertos são os limites de atuação tanto do Estado que faz a solicitação quanto da própria ONU.

Buscando ilustrar e ao mesmo tempo entender os últumos fatos históricos de conflitos armados, o estudo foca o conflito entre Iraque e Estados Unidos da América, principalmente no lapso temporal de 1990 até 2003.

Assim, a legitima defesa, direito consagrado universalmente, previsto no texto da carta pode ser exercido de forma individual e coletivo, quando um membro das Nações Unidas é objeto de uma agressão armada ${ }^{15}$.

Nos termos do artigo em epigrafe, somente a efetiva agressão armada, e não qualquer coação, legitima o recurso à força a título de legítima defesa, cabendo ao Conselho de Segurança a competência de manter a paz através dos recursos bélicos das Nações Unidas ou de seus Esrados.

Realizar medidas necessárias para se manter a paz é uma função um tanto quanto abstrata e complexa, pois difícil precisar quais são tais medidas. Assim, o instrumento jurídico conferido ao Conselho de Segurança, qual seja a resolução, carece de efetividade haja vista seu conteúdo recomendativo.

No tocante ao exercício do direito de legítima defesa coletiva, o Estado membro da ONU e vítima de agressão armada pode solicitar uma intervenção, como foi o caso verificado no processo do Golfo ". A pedido do Kuwait, invadido pelo Iraque, em agosto de 1990, que um grupo de Estados toma as primeiras iniciativvas diplomáticas, econômicas e militares com vistas a restabelecer a autoridade legítima sobre este território.

Quando o Iraque invadiu o Kuwait em 2 de Agosto de 1990, a sociedade internacional e principalmente o Conselho de Segurança da ONU, que por quase meio século ficou imobilizado pela Guerra Fria e pelo veto das grandes potências para proteger seus aliados, deparou-se com o desafio de aplicar o principio a regra da legitima defesa coletiva.

15 vide artigo 51 da Carta das Nações Unidas.

${ }^{16}$ DINH, Nguyen Quoc; DAILLER, Patrick Et PELLET, Alain. Op. Loc. Cit. p.826 
Ao invadir e anexar o Kuwait, Saddam Hussein foi contra as regras do direito internacional que probibiam o uso da força No mesmo dia que o Iraque anexou o Kuwait, o Conselho de Segurança decretou na Resolução $660^{17}$, dentro do Capítulo VII da Carta, que a invasão fora uma quebra da paz e seguridade internacional e ordenou a retirada imediata das tropas iraquianas.

Diante da telutância do Iraque em cumprir a Resolução 660, o Conselho de Segurança adotou a Resolução $661^{18}$ impondo sanções econômicas contra o Iraque - o total embatgo comercial e o congelamento de bens Iraquianos no exterior.

Entretanto, nem isso persuadiu o Iraque a retirar suas tropas do Kuwait. Assim, em 29 de Novembto de 1990, o Conselho de Segurança aprovou a Resolução 678" demandando a retirada das tropas Iraquianas do Kuwait até o prazo limite de 15 de Janeiro de 1991, e autorizando os Estados-membros cooperando com o Governo do Kuwait a tomar todos os meios necessários (leia-se ataque militar) para implementar a Resolução 660 (retirada das tropas Iraquianas) e a restaurar a paz e seguridade na região.

A Resolução 678 é importantíssima para a analise dos reflexos legais com relação ao uso da força no presente caso. Até a tomada da Resolução 678, o Kuwait e os Estados aliados ao Governo Kuwaitiano poderiam atacat as tropas Iraquianas com base no direito de autodefesa coletivo. Porém, teriam o limite legal de poder somente retirá-las do Kuwait.

Com a aprovação da Resolução 678 a ação militat transferiu-se do âmbito de autodefesa coletivo ou individual (do Kuwait ou eventualmente da Arábia Saudita) para o de uma ação militar autorizada pelo Conselho de Segurança, e com o adendo de restaurar a paz e seguridade na região, ou seja, um mandato muito mais amplo, autorizando até, se necessária, a ida das tropas aliadas à Bagdá para a retirada de Saddam Hussein.

Retoma-se aqui o salientado alhures, a difícil intetpretação da amplitude e dos limites de ação do Conselho de Segurança. As hostilidades começaram após o prazo final de 15 de Janeiro de 1991 e terminaram cerca de seis semanas depois quando as tropas da coalização, depois da libertação do Kuwait, foram ordenadas pelo Presidente Bush em 28 de Fevereiro de 1991 a cessarem o ataque.

O Conselho de Segurança mediante a Resolução $687^{20}$ impôs os requisitos ao Iraque para o cessar fogo. Os mais importantes requisitos impostos ao Iraque foram: (i) libertação

17 Resolução 660 de 02 de agosto de 1990, ditada pelo Conselho de Segurança das Naçoes Unidas. Disponivel no site da ONU in: http://www un.org/spanish/docs/sc90/scres $90 \mathrm{htm}$

${ }^{18}$ Resoluçăo 661 de 06 de agosto de 1990, ditada pelo Conselho de Segurança das Naçôes Unidas. Disponivel no site da ONU in: http://www.un.org/spanish/docs/sc90/scres90htm

19 Resolução 678 de 29 de novembro de 1990, ditada pelo Conselho de Segurança das Nações Unidas. Disponivel no site da ONU in: http://www.un.org/spanish/ctocs/sc90/scres $90 . h t m$

${ }^{20}$ Resolução 687 de 03 de abril de 1991, ditada pelo Conselho de Segurança das Naçóes Unidas. Disponivel no site da ONU in: http://wwwiun.org/spanish/docs/sc91/scres91.htm. 
dos prisioneiros de guerra; (ii) devolução dos bens saqueados do Kuwait; (iii) pagamento de compensação pelos prejuizos causados pela invasão ilegal do Kuwait e pelas hostilidades subseqüentes; (iv) autotização de inspeções de suas facilidades nucleares eligadas a armas de destruição em massa, conseqüente destruição das armar de destruição em massa e de mísseis balísticos de longa distância e de toda capacitação para construí-los; e (v) encerramento de ajuda a grupos terroristas.

Todavia, apesar da norma acima mencionada, o Iraque descumpriu os requisitos estabelecidos pela ONU. O Governo Iraquiano nunca devolveu os bens roubados do Kuwait, recusou-se a pagar os prejuizos causados pela invasão ao Kuwait (recusou um acordo que permititia ao Iraque voltar a vender livremente o seu Petróleo se $30 \%$ do valor fosse destinado a pagar os prejuizos causados ${ }^{21}$, nunca cooperou integralmente com os inspetores de armas (só resolvia abrir seus complexos e dossiês quando havia a ameaça séria do uso da força, como em 1998), e financiava (em tese) grupos terroristas, especialmente palestinos (como envio de dinheiro aos familiares dos homens-bomba).

Entretanto, mesmo com a clara violação pelo Iraque dos requisitos estabelecidos para o cessar fogo, o uso da força contra o Iraque só poderia ser novamente justificado se estivesse dentro de uma das rrês exceções que possibilitam o uso da força no direito internacional, conforme acima descrito. Resta saber se a Segunda Guerta do Golfo se enquadra em uma delas.

As alegações norte-americanas de que o regime de Sadan Hussein, fragilizado pela I Guerra do Golfo e pelo embargo dela decorrente, ameace de fato os EUA ou o Reino Unido, para que estes de boa fé invoquem a legítima defesa. As alegações de participação do Iraque nos terriveis acontecimentos de 11 de setembro também não foram comprovadas.

Ainda mais, o argumento de que o Iraque estaria desenvolvendo programas de armas de destruição em massa carece de legitimidade, pois a avaliação deveria ser feita pelos inspetores das Nações Unidas e não unilateralmente por dois Estados membros desta Organização. Assaz ressaltar que até o momento, estas ainda não foram encontradas pelas forças de ocupação. Finalmente, o direito internacional desconhece o conceito de legitima defesa preventiva ${ }^{22}$ tantas vezes argüido, visando desviar o reconhecimento da ilegalidade do fato.

A legalidade, no caso, do recurso a fotça residente em uma ação individual ou coletiva, pode ainda ser resultante de uma decisão do Conselho de Segurança fundada no Capítulo VII da Carta. A questão que se coloca, portanto, é a de saber se houve ou não uma autorização neste sentido.

${ }^{21}$ Vide fatos que marcaram a história: http://www.conhecimentosgerais.com.br/historia-geral/guerrado-golfohtml.

${ }^{22}$ DINH, Nguyen Quoc; DAILLER, Patrick Et PELLET, Alain. Op. Loc. Cit. p.827. 
Assim, além do cessar fogo estabelecido pela resolução 687 de 1991 do Conselho de Segurança, foi criado a UNSCOM - Comissão Especial das Nações Unidas, que tem por principal objetivo realizar inspeções no Iraque em matérias de armas biológicas, químicas e mísseis com alcances de mais de $150 \mathrm{~km}$.

Durante as inspeções, nuitos foram as dificuldades oferecidas pelo Iraque aos inspetores, que em janeiro de 1998 foram proibidos de entrar em território iraquiano ${ }^{23}$, sendo que somente em setembro de 2002 o Ministro das Relações Exteriores do Iraque informou que o governo havia autorizado o retorno dos inspetores ${ }^{24}$.

Diante deste contexto, em novembro de 2002, o Conselho de Segurança aprova por unanimidade a Resolução $1441^{2.5}$ que confere ao Iraque a oportunidade de desarmamento. De fato, tal resolução reconhece que o Iraque desrespeitou a obrigação de se desarmar, conforme previsto na resolução 687 de 3 de abril de 1991, que estabeleceu o fim da I Guerra do Golfo. É também que a resolução 1441 adverte o Iraque das graves conseqüiências possiveis decorrentes $\mathrm{da}$ continuação do desrespeito a suas obrigaçöes internacionais.

Somente a Resolução 1441, aprovada pelo Conselho de Segurança por unanimidade em 8 de novembro de 2002, até com grande surpresa para os Estados Unidos e a GrãBretanha que não esperavam os votos favoráveis de França e Rússia, poderia se enquadrat dentro de uma das hipóteses de autorização do uso da força armada.

A Resolução 1441 não caracteriza nenhuma ação do governo Iraquiano como uma nova agressão, ameaça à paz ou quebra da paz. A Resolução lida somente com as questões da Primeira Guerra do Golfo e com as Resoluçōes e circunstâncias conseqüentes da mesma.

Todavia questiona-se se a Resolução 1441 encontra-se na hipótese de autorização do Conselho de Segurança, ou seja, se a resoluçâo afirmou que o Iraque estaria descumprindo os requisitos do cessar fogo e reviveu a Resolução que autorizou as ações militares da Primeira Guerra.

Sob a ótica da busca pela solução pacífica dos conflitos, em um dos momentos de tensão no Conselho de Segurança das Nações Unidas sobre a decisão do uso da força, seus membros permanentes como França e Rússia, países com direito a veto, deixaram bem claro

${ }^{23}$ ARAÚO, Bruno Manoel Viana de. Antecedentes da guerra contra o Traque baseados em documentos internos das Nações Unidas. Jus Navigandi, Teresina, a. 8, n. 267, 31 mar. 2004. Disponivel em: <http:/ /www1.jus.com.br/doutrina/texto.asp?id $=5023>$

${ }^{24}$ Em cumprimento do paráarafo 12 da Resoluçào 1284, de 17 de dezembro de 1999, do Conselho de Segurança das Naçóes Unidas, o Secretário Geral transmite ao Conselho de Segurança o décimo primeiro informe trimestral apresentado pelo Presidente Executivo da UNMOVIC (doc. S/2002/ 1303).

${ }^{25}$ Resolução 1441 de 08 de novembro de 2002, do Conseho de Segurança das Nações Unidas aprovada na sua $4644^{2}$ sessão (doc. S/RES/1441) Disponivel no site da ONU in: http:/www.un.org/spanish/ docs $/ \mathrm{sc02} / \mathrm{scrl02}$ htm 
que não aprovariam uma resolução que autorizasse o uso da força $a^{26}$, e que como membros permanentes do Conselho de Segurança das Nações Unidas assumiriam todas suas responsabilidades a este respeito, desde que permanecesse o quadro atual de cooperação do Iraque, cumprindo com todas as exigências impostas.

Em reunião do Conselho de Segurança das Nações Unidas em 16 de março de 2003, a maioria dos membros decidiu não apoiar um projeto de resolução agressiva e bélica que permitisse o uso da força contra o Iraque ${ }^{27}$.

Todavia, em 18 de março de $2003^{28}$, o Presidente dos Estados Unidos Geroge W Bush Jr, com apoio da Inglaterra, faz um ultimo aviso ao Presidente do Iraque Saddam Husseim, para em 48 horas abandonar o Iraque e evitar a guerra. A ofensiva militar teve inicio na madrugada de 20 de março de 2003.

$\mathrm{Na}$ Resolução 1441, o Conselho de Segurança reafirma a Resolução 678 que autorizon os Estados Membros a usar todos os meios necessários (leia-se ataque militar) para implementar a Resolução 660 e Resoluções subseqüentes e a restaurar a paz e a seguridade na região.

A Resolução ressalta a Resolução 687 que impôs as obrigações ao Iraque para o cessar fogo, deplorando que o Iraque não tenha providenciado uma abertura precisa, total, final e completa de todos os aspectos dos seus programas de desenvolvimento de armas de destruição em massa e mísseis balísticos, e que o Govemo do Iraque tenha falhado en cumprir com as obrigações com relação a terrorismo, repressão à população civil e devolução de todos os bens e prisioneiros retirados do Kuwait.

A afirmação mais importante da Resolução 1441 está contida no primeiro parágrafo, onde o Conselho de Segurança decide que o Iraque tem estado epermanece em violação substancial das obrigaçóes contidas nas resoluções, incluindo a Resolução 687.

Diante do exposto resta a pergunta: o Conselho de Segurança decidiu que o lraque quebrou os requisitos do cessar fogo da Resolução 687 e reviveu a Resolução 678 que autorizou o ataque militar contra o Iraque para restabelecer a paz e seguridade na região? $\mathrm{Ou}$ os Estados Unidos infrigiram as regras de limitação ao uso da força e invadiram território iraquiano, dando a eles o direito a legitima defesa?

${ }^{26}$ Carta de 05 de março de 2003, dirigida ao Presidente do Conselho de Segurança pelos Representantes Permanentes de Alemanha, da Fedetação de Rússia e de França (doc. S/2003/253). In; www.un.org

${ }^{27}$ Carta do Representante Permanente do Iraque Mohammed A. Aldouri, dirigida em 21 de março de 2003, ao Secretário-Geral das Naçōes Unidas.(Doc. S/2003/358).

${ }^{28}$ Vide site da $\mathrm{BBC}$ no Brasil: http://www.bbc.co.uk/portuguese/ 


\section{REFERÊNCIAS BIBLIOGRÁFICAS}

DREIFUSS, RENÉ ARMAND A época das perplexidades: mundialização, globalização e planetarização - novos desafios. Petrópolis, RJ : Vozes, 1996.

DINH, Nguyen Quoc;DAILLER, Patrick Et PELLET, Alain. Direito Intennacional Publico, tradução do original Droit Internacional Public por Vitor Marques Coelho, Lisboa: Fundação Calouste Gubernkain, 1999.

RAMINA, Larissa, A doutrina Busho e a Resolução 1441 do Conselho de Segurança das Nações Unidas na ótica do Direito Internacional. In : D'ANGELIS, Wagner Rocha (org). Direito Internacional do século XXI : integração, justiça e paz., Curitiba : Juruá, 2003.

TRINDADE, Antonio Augusto Cançado. O Direito Internacional em um Mundo em Transformação. Rio de Janeito : Renovar, 2002.

ARNAUD, André-jean O Direito entre Modernidade e Globalização : Lições de flilosofia do Direito e do Estado. Rio de Janeiro : Renovar, 1999.

Organização das Nações Unidas in: http://www.un,org/spanish/aboutun/growth.htm, acessado em 01 de julho de 04.

HOUAISS, Antonio e VILLAR, Mauro de Salles. Dicionário Houaiss da Língua Portuguesa, elaborado pelo instituto Antonio Houaiss de Lexicografia. Rio de Janeiro: Objetiva, 2001.

Texto integral da Carta das Nações Unidas disponivel no site oficial da ONU in: http:// www.un.org/spanish/aboutun/charter/index.htm

MELLLO, Celso D de Albuquerque.Curso de Direito Internacional Público, $2^{\circ}$ vol, $13^{\circ}$ edição revista e aumentada, Rio de Janeiro: Renovar, 2001.

SWINARSKI, Christophe. A Norma ea Guerra : palestras sobre direito internacional humanitário. Porto Alegre: Sergio Antonio Fabris Editor, 1991.

Resolução 660 de 02 de agosto de 1990, ditada pelo Conselho de Segurança das Nações Unidas. Disponivel no site da ONU in: http://wwwun.org/spanish/docs/sc90/ scres $90, \mathrm{htm}$

Resolução 661 de 06 de agosto de 1990, ditada pelo Conselho de Segurança das Nações Unidas. Disponível no site da ONU in: http://www.un.org/spanish/docs/sc90/ scres90.htm

Resolução 678 de 29 de novembro de 1990 , ditada pelo Conselho de Segurança das Nações Unidas. Disponível no site da ONU in: http://www.un.org/spanish/docs/sc90/ scres 90. htm 
Resolução 687 de 03 de abril de 1991, ditada pelo Conselho de Segurança das Nações Unidas. Disponivel no site da ONU in: http://wwwun.org/spanish/docs/sc91/scres91.htm.

ARAÚJO, Bruno Manoel Viana de. Antecedentes da guerra contra o Iraque baseados em documentos internos das Nações Unidas . Jus Navigandi, Teresina, a. 8, n. 267, 31 mar. 2004. Disponivel em: <http://wwwl.jus.com.br/doutrina $/$ texto.asp?id $=5023>$

Resolução 1441 de 08 de novembro de 2002, do Conselho de Segurança das Nações Unidas aprovada na sua $4644^{2}$ sessão (doc. S/RES/1441) Disponivel no site da ONU in: http:/ /www.un.org/spanish/docs/sc02/scrl02.htm

Carta de 05 de março de 2003, dirigida ao Presidente do Conselho de Segurança pelos Representantes Permanentes de Alemanha, da Federação de Rússia e de França (doc. S/ 2003/253). In: www.un.otg

Carta do Representante Permanente do Iraque Mohammed A. Aldouri, ditigida em 21 de março de 2003, ao Secretário-Geral das Nações Unidas.(Doc. S/2003/358). 